Natasha Williams and Shalu Gillum

\title{
Encouraging users to pop in Popcorn Day in the medical library
}

$\mathbf{N}$

ew libraries are constantly challenged to adapt how their spaces are used. This is the case even more so for libraries with primarily digital collections. As a brand new 21st-century library with only a few print materials and a 98\% digital collection, it was important for the University of Central Florida Harriet Ginsburg Health Sciences Library to promote use of our space to existing users, and to establish the library space itself as a valuable resource to its faculty, staff, and students. This would be ac-

complished through The library's famous popcorn machine. to rebuild relationships with its old and new faculty and staff, and to encourage medical students to enter the library. Additionally, because our collection is almost entirely digital, students can access

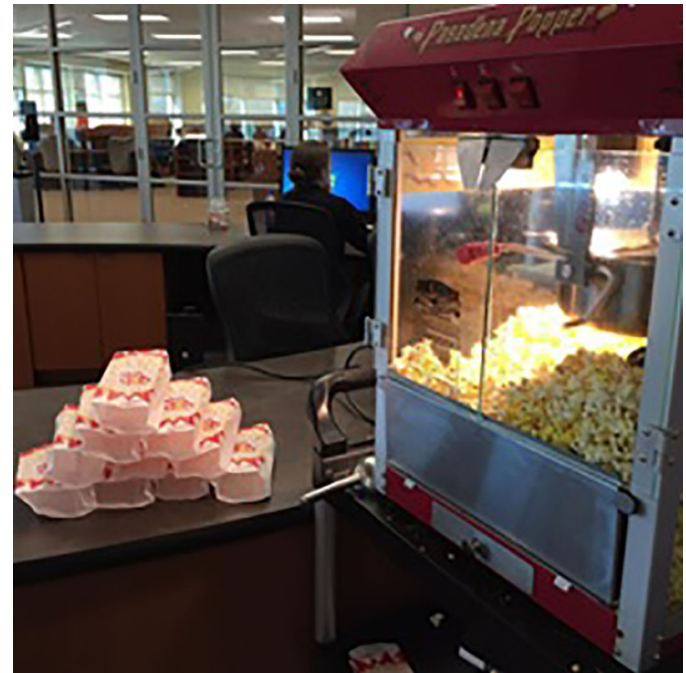
our resources without having to step foot in the physical library space. The library team also hoped that while students, faculty, and staff came to enjoy their popcorn, the library would have an opportunity to share information about library resources and services. Finally, having a unifying event for the entire college novel outreach activities, including one of our more unique and successful experiences-Popcorn Day.

The library established its weekly Popcorn Day promotion to attract students, faculty, and staff to the library space. When the College of Medicine (COM) moved into its new building in 2010 from its previous home occupying one floor of a research building, the small and close-knit COM family suddenly dispersed. The library needed a way would create a welcoming and inviting place for the COM community to gather and network.

Natasha Williams is user services librarian, email: natasha.williams@ucf.edu, and Shalu Gillum is head of public services, email: shalu@ucf.edu, at the Harriet F. Ginsburg Health Sciences Library in the University of Central Florida College of Medicine

(C) 2018 Natasha Williams and Shalu Gillum 


\section{Popcorn Day is born}

The idea for Popcorn Day was born out of a library team brainstorming session after the 2011 Medical Library Association annual meeting in Minneapolis, Minnesota. The library's public services librarian attended a continuing education program called, "Marketing as if Your Library Depended on it," during which participants brainstormed ideas for unconventional programming. From her long list of ideas, which she shared with her li-

brary team, having popcorn in the library was the unanimous choice because it sounded like the easiest and most fun idea for program ming. There was very little risk involved, other than purchasing a popcorn machine and supplies.

\section{Logistics}

We decided it would be most effective and time-efficient to purchase a full-size popcorn machine rather than making microwave popcorn for the event. A full-size machine would pop popcorn in larger batches, keep the popcorn warm for the duration of the event, and generate greater interest for the event by acting as an attractive and eye-catching prop. An appropriately sized machine and associated supplies (e.g., popcorn and paper bags) were purchased online from Amazon.com.

When considering the timing of the event, it was important to establish some consistency so that Popcorn Day could become a regular part of our patrons' schedules. This way everyone could look forward to the weekly event without having to keep track of a fluctuating appointment. We determined that Thursday afternoons at 3 p.m. would be our best bet. A few factors went into choosing this day and time. First, we recognized that choosing one day out of the week would generate more excitement than choosing multiple days because the novelty would not wear off as fast. Additionally, we chose Thursday because it created an added feeling of a morality boost being so close to the end of the week. We also tried to be conscious of monopolizing too much faculty and staff time. A more than once-weekly event could put additional stress on already maxed-out daily schedules full of meetings, and we did not want our event to compete or be seen as frivolous in comparison.

With respect to choosing the start time, we knew the event would not be successful if it occurred too close to the lunch hour. We figured that 3 p.m. was far enough away from lunch that patrons would be interested in taking a break from studying and working, and more likely in the mood for a snack. Student schedules were also taken into account when choosing the start time for the event.

One member of the library team was designated the official popcorn popper (over time, other library staff members were also trained as backup poppers). The popcorn takes approximately half an hour to pre- 
pare. Initially, we had planned to pop the popcorn within the library space, but we were advised to find another location, due to concerns about the sensitivity of the emergency sprinkler systems within the building. We tried several other locations around and outside the building before settling upon the kitchen located in the library breakroom. A window is propped open for the duration of the popcorn preparation to let any steam from the machine escape outside. finished with classes by 3 p.m. and are free to participate in Popcorn Day, second-year students are usually in the middle of lecture during this time, but have been known to request a five-to-ten-minute break that coincides with the start of the event.

As we had hoped, Popcorn Day has also increased librarian engagement with our users. Members of the library's Public Services team are on hand during Popcorn Day to help distribute popcorn and to interact with attend-

\section{Promoting Popcorn Day}

Advertising for Popcorn Day is very straightforward. created two flyers to be placed in each of the elevators within the medical education building, and a 24" x 36" during Popcorn Day.

poster-sized version of the flyer to be placed outside of the library each Thursday morning. The flyers and poster are removed once all of the popcorn has been consumed, or by the end of the business day, depending on which occurs first.

\section{Outcomes and observations}

Six years after the initial idea to start a weekly popcorn outreach activity, Popcorn Day is still by far our most popular and effective method to draw people into the library space. The event is so popular that beyond the flyers and poster, no advertising is needed on our part. Since then, regular Popcorn Day participants have let us know that they have added reminders to their calendars so as not to miss the event. While first-year medical students are ees. Because library staff is so visible during this time, it gives medical students the chance to ask any questions they might have. Due to the informal nature of the event, with attendees mingling and chatting around the library front desk, more opportunities are created for relationship-building between the library team and its users. Library staff are also able to meet and engage with COM faculty and staff that may not otherwise step foot in the library.

Popcorn Day has also contributed to the general goodwill towards the library. We have received so much positive feedback from students, staff, and faculty that the event is a highlight of their week, that it builds consistency in otherwise crazy schedules, and that it is plain fun. When prospective medical students are led on tours of the library space by current students, Popcorn Day is often mentioned as a special library offering unique to COM.

Finally, Popcorn Day has increased the overall foot traffic into the library, which was our ultimate goal. Statistics from our automatic 
gate counters show the growth in use our library has experienced, as well as noticeable spikes in activity on Thursdays. When Popcorn Day was introduced during the 2011-12 academic year, the library saw an average of 115 people come through the library per day, with an average of 160 people on Thursdays due to Popcorn Day. Six years later, the library now sees an average of 305 people each day, and an average of 377 on Popcorn Day. We believe that our internal outreach efforts, including Popcorn Day, were a contributing factor to the increased use of the library space.

\section{The evolution of Popcorn Day}

Popcorn Day has evolved in that it has been a way for the library to participate in other college-wide initiatives. For example, during Diversity Week, the library offers several popcorn toppings from various countries, including snacks and spices from across the globe. The idea for offering popcorn toppings came from a regular Popcorn Day attendee, and the library adopted the concept as "Magical MixIns," which we now offer twice a year, including during Diversity Week.

\section{Conclusion}

The library's weekly Popcorn Day outreach event has established the library as a fun and inclusive environment on the COM campus. It is our most popular outreach activity, and encourages use of the library space, as well as engagement between the library team and all of its users. ${ }^{2}$

\section{Notes}

1. Special thanks to everyone who enjoys Popcorn Day as enthusiastically as the persons included in our photos.

2. Visit us on Instagram to view more pictures of Popcorn Day and other library outreach activities at http://www.instagram. com/ucfcomhsl. n

("Hidden science superstars" continues from page 382)

2. See www.ala.org/news/press -releases/2017/01/acrl-board-directors -affirms-commitment-equity-diversity -inclusion-access.

3. See www.ala.org/news/press -releases/2016/10/acrl-diversity-alliance-launches.

4. See www.ala.org/acrl/aboutacrl /directoryofleadership/committees/acr-raed.

5. See www.ala.org/acrl/standards /diversity.

6. See www.ala.org/advocacy/diversity.

7. See www.ala.org/acrl/membership /mentoring/joseymentoring/mentorprogram for example.

8. I was privileged to be invited to review an advance copy and provide a cover blurb. It will be available in 2018 .

9. Teresa Y. Neely and Khafre K. Abif, eds. In Our Own Voices: The Changing Face of Librarianship (Lanham, M.D.: Scarecrow Press, Inc., 1996).
10. See https://www.wooster.edu /students/diversity/.

11. You can read more about McCulloch and the statue at www.the-daily-record. com/news/20170307/mcculloch-statue -dedicated-at-college-of-wooster.

12. See https://www.wooster.edu /about/facts/.

13. For the LibGuide see http://libguides. wooster.edu/science-superstars. The Wooster Voice article is at http://thewoostervoice. spaces.wooster.edu/2017/09/29/timken -library-seeks-to-celebrate-underrepresented -figures-in-science/.

14. See https://library.ohio.gov /documents/open-rfp/.

15. See https://www.wooster.edu /students/diversity/msa/mlk/dialogues/.

16. See https://www.wooster.edu /about/leadership/president/ and https://www. wooster.edu/bios/cnewton/. ュ 